\title{
A AUTONOMIA PROFISSIONAL E AS REFORMAS EDUCACIONAIS DOS ANOS 1990: LIMITES E POSSIBILIDADES
}

\author{
Adriana Ribeiro dos Santos Quintanna ${ }^{(*)}$ \\ Ednacelí Abreu Damasceno ${ }^{(* *)}$
}

Este trabalho é resultado das discussões desencadeadas no contexto da disciplina "Formação e Trabalho Docente: representações, saberes e práticas" ofertada pelo Programa de Pós-graduação em Educação (PPGE) da Universidade Federal do Acre (UFAC). A partir das discussões desencadeadas no decorrer da disciplina acerca de tantos aspectos extremamente importantes para uma compreensão aprofundada da Formação e do Trabalho Docente surgiu o interesse por um aprofundamento de estudos acerca da autonomia. Trata-se de um estudo de natureza bibliográfica, cujas fontes de pesquisa foram livros e artigos em que se discute o tema, em que, prioritariamente, os materiais para coleta de dados foram aqueles indicados na ementa da disciplina.

O Trabalho Docente pode ser discutido a partir de diferentes aspectos, tendo como pano de fundo outros tantos. Discutir o Trabalho Docente não é uma tarefa simples, por se tratar em si mesmo de uma temática complexa e que passou (e passa) por mudanças continuamente, num processo de vaivéns, de rupturas, de mudanças e de permanências. Essas mudanças geralmente decorrem de outras, seja no cenário econômico, político, cultural, social ou nas próprias concepções acerca do processo de ensino-aprendizagem. A escola e, portanto, o trabalho do professor, não estão isentas ou não podem ser mantidas neutras, intactas ante as mudanças sociais.

Neste sentido, este trabalho foi construído na perspectiva de apresentar uma discussão acerca das reformas educacionais que ocorreram a partir dos anos de 1990 no Brasil, do século XX e como elas impactaram o trabalho docente e, consequentemente, a autonomia profissional do professor.

O trabalho docente não pode ser visto ou compreendido como um objeto alheio às mudanças na política, na economia ou na cultura. Antes, carece ser analisado à luz dessas mudanças, para que dessa forma, possa-se identificar os conflitos e contradições que perpassam esse trabalho.

\footnotetext{
${ }^{(*)}$ Mestranda do Programa de Pós-graduação em Educação da Universidade Federal do Acre. Graduada em Pedagogia pela Universidade Federal do Acre. Ordic: <https://orcid.org/0000-0002-5151-383X $>$. E-mail: adrianaribeiro dossantos 34@gmail.com.

${ }^{(* *)}$ Doutora em Educação pela Universidade Federal de Minas Gerais. Professora do Programa de Pós-Graduação em Educação da Universidade Federal do Acre. Orcid: https://orcid.org/0000-0002-3859-6423>. E-mail: ednaceli @yahoo.com.br.
} 
A questão da autonomia docente não é um assunto recente, a partir dos estudos de Catani (2000) podemos identificar que há tempos a temática vem sendo motivo de discussão e de reivindicação dessa classe trabalhadora. O fato é que, de acordo com essa autora, a partir dos anos 1990, essa temática adquire certa centralidade nos debates educacionais. Corroborando com isso, Contreras (2012) afirma que "a autonomia dos professores, bem como a própria ideia de seu profissionalismo, são temas recorrentes nos últimos tempos nos discursos pedagógicos” (p. 27), sobretudo no contexto das reformas educacionais. As reformas educacionais ocorridas a partir dos anos 90 do século XX, no Brasil, desencadeadas pelas mudanças nas políticas e concepções educativas, procuraram reforçar no discurso a autonomia do professor, alocando os alunos e os métodos de ensino na centralidade dos processos educativos, e quanto ao papel do professor tendem a reforçar o seu protagonismo e a elencar a autonomia como elemento essencial para o desenvolvimento do aluno e para o êxito dos programas que seriam implantados. No entanto, isso não necessariamente significa um maior poder docente em relação às tomadas de decisão. Pacheco afirma que "o discurso da autonomia pode desempenhar uma poderosa função ideológica estimulando o sentido da eficácia pessoal, mas também promovendo a subordinação do indivíduo ao controle organizativo" (PACHECO, 2010, p.116).

A partir dessa afirmação, podemos perceber que o termo autonomia está envolto em significados não apenas diferentes, mas também opostos. Ele pode ser compreendido não somente como a possibilidade de maior controle e poder do docente sobre a atividade que ele desempenha, ou até mesmo de uma condição em na qual o professor não precisa dar "satisfações" a ninguém, quanto como uma maior responsabilização dos docentes pela eficácia do seu trabalho, mesmo quando este se enxerga (ou é enxergado) apenas como mero executor de tarefas.

Sendo a autonomia um tema tão relevante para o trabalho docente, a perspectiva nesse texto é perceber quais os seus significados e de que forma a autonomia docente é conceituada e, além disso, compreender quais mudanças as reformas educacionais tem incidido sobre o trabalho do professor, limitando-a, mas também construindo espaços de confronto e resistência.

O texto encontra-se organizado em sua primeira parte, a discussão teórica de estudos que apresentam algumas definições a respeito da autonomia no trabalho docente. Em seguida, apresenta-se, ainda que de forma parcial, o contexto das reformas das últimas décadas e seus efeitos no trabalho docente. Na terceira parte apresentam-se alguns impactos que essas reformas exercem sobre a autonomia do professorado, com ênfase nos limites e nas possibilidades de construção da autonomia pelo professor. E, por fim, se tece algumas considerações finais, porém não definitivas, nem inquestionáveis. Vale salientar, que o objetivo aqui, dada a natureza e as limitações deste 
trabalho, não é o de esgotar essa discussão, nem há a pretensão de estabelecer discussões inquestionáveis ou fornecer "receitas" que deem conta de dizer ao professor "o quê" ou "como fazer" o seu trabalho de forma autônoma. As proposições ora apresentadas, são na verdade provocações ao questionamento, a reflexão e ao debate.

\section{AS REFORMAS DOS ANOS 1990: OS IMPACTOS NO TRABALHO DOCENTE}

Transformações são comuns na história de uma forma geral. Elas ocorrem em todos os âmbitos de uma sociedade: na cultura, na economia, na política, etc. A educação não somente é afetada por essas transformações, como ela mesma, por vezes é propulsora delas, tendo como base uma análise sociológica pautada no "otimismo crítico" tal como apontado por Cortella (1998), em que é possível compreender que a escola não apenas reproduz e conserva, mas também é instrumento de inovação e mudança, assumindo uma natureza contraditória.

Dito isto, depreende-se que a história da educação, da escola e, consequentemente, do trabalho docente assume características especificas a depender do contexto em que está inserido. Dessa forma, em cumprimento aos objetivos propostos, nesta seção busca-se apresentar o contexto de reformas que se desencadeia nos anos 1990, no Brasil de que forma elas afetaram o trabalho do professor e quais os limites à construção da autonomia profissional nessa conjuntura.

É consenso entre autores como Pimenta (2002); Cunha (2013); Ludke e Boing (2004); Freitas (2003); Giroux (1997); Nóvoa (1999); Contreras (2012) e Oliveira (2004) reconhecer que a década de 1990 "inaugura um novo momento na educação brasileira” (OLIVEIRA, 2004, p. 1129). Ainda de acordo com Oliveira

As reformas educacionais iniciadas na última década no Brasil e nos demais países de América Latina têm trazido mudanças significativas para os trabalhadores docentes. São reformas que atuam não só no nível da escola, mas em todo o sistema repercutindo em mudanças profundas na natureza do trabalho escolar (2004, p. 1128)

É salutar compreender que essas mudanças no contexto escolar se desencadeiam muito em função do avanço do neoliberalismo nos anos 90 do século $\mathrm{XX}$ mundo afora. No contexto brasileiro, temos o "encolhimento do estado", "o reconhecimento do mercado" como eixo central das relações sociais e dessa forma escolas e universidades se veem em um "embate entre a democratização e a resposta às exigências de um mundo produtivo cambiante" (CUNHA, 2013, p. 616). Desse modo os impactos sobre a Formação e o Trabalho Docente são quase inevitáveis.

A implantação da lógica do mercado em todas as instituições e esferas da vida social e cultural tem sido o caminho trilhado pelo neoliberalismo para conquistar a hegemonia 
econômica e política [...] essa reestruturação da sociedade, como já foi assinalada, tem requerido uma reestruturação da educação [...] os efeitos sobre o trabalho docente são profundos (HYPOLITO; VIEIRA; PIZZI, 2009, p. 106).

Outra consequência apontada nos estudos de Cunha (2013) diz respeito às políticas regulatórias de avaliação que atuaram para definir de "forma reducionista, o que se constitui como valor na educação e a consequente burocratização do trabalho docente impactou o exercício da profissão" (p. 618).

De acordo com Ball (2002) essas reformas afetam o trabalho e, consequentemente, a identidade do professor, quem ele é, porque "as tecnologias políticas da reforma da educação não são simplesmente veículos para a mudança técnica e estrutural das organizações, mas também mecanismos para reformar professores". Dessa forma, pode-se depreender que essas mudanças impactam diretamente o trabalho do professor, em que, no caso das avaliações externas, por exemplo, passa a ser regulado por políticas avaliativas que em maior ou menor medida são instrumentos de controle daquilo que o professor faz e condicionam suas escolhas.

Esse contexto de reformas também tem como característica marcante a disseminação do discurso das competências (LUDKE; BOING, 2004; CUNHA, 2013) e isso impactou o trabalho do professor colocando-o como figura central no alcance dessas competências por parte dos alunos. Dessa forma o professor adquire um papel de centralidade frente ao êxito dos programas e além disso ele se vê "diante das variadas funções que a escola pública assume, tem de responder a exigências que estão além da sua formação" (OLIVEIRA, 2004, p. 1132) e que, por vezes contribuem para a perda do eixo central da atividade docente, que é o ensino, ficando este como uma natureza secundária do trabalho docente. Corroborando com isso, Contreras (2012) afirma que são cada vez maiores as funções atribuídos ao ensino, pretendendo-se que os docentes atendam a esferas da educação cada vez mais difusas e ambíguas (ORTEGA, 1992), e onde se espera que a educação dê respostas a problemas cada vez mais complexos sobre as crises econômicas, sociais e culturais de nossa sociedade (APPLE, 1989b). Isto faz com que aumente nos professores o sentimento de responsabilização e culpa em relação ao que no fundo são problemas complexos de ordem institucional e social (p. 167).

A culpabilização dos professores pelas mazelas educacionais e sociais não apenas é injusta, mas também simplória, tendo em vista que são inúmeras e complexas as questões sociais que perpassam o trabalho do professor e sobre os quais ele não tem controle e além disso uma melhor compreensão não pode prescindir de uma análise das condições objetivas de trabalho do professor. 
Além do crescente processo de precarização e flexibilização (OLIVEIRA, 2004), de intensificação e autointensificação (HYPOLITO; VIEIRA e PIZZI, 2009), da precariedade da Formação (GATTI, 2013), de regulação e controle por meio das avaliações externas (FREITAS, 2013), da desprofissionalização e desvalorização (LUDKE e BOING, 2004) entre outros dilemas, frente a essas modificações e a esse controle sobre o trabalho docente, a autonomia do professor tem um processo de declínio. O paradoxo que se apresenta nesse contexto é que, se por um lado, o papel do professor assume uma centralidade nos discursos políticos, por outro não lhes é oportunizado a participação nos processos de configuração dessas políticas. Outras instâncias planejam e decidem e os professores executam, o que Contreras (2012) denomina de "Autonomia aparente".

Que esta aparente autonomia não significa grande capacidade de ação é demonstrada pelo fato de que a capacidade de decisão e intervenção só é "concedida" a partir da escola, com os professores sendo excluídos de todos os pressupostos, condições e organizações prévias (CONTRERAS, 2012, p. 290)

Ou seja, o discurso acerca da autonomia do professor acontece de cima para baixo, não caracterizando uma "autonomia política", mas apenas uma "autonomia de gestão" para resolver os problemas mais imediatos de sua ação. Para além disso, por muitas vezes, esse discurso aponta para uma maior responsabilização do professorado pelo êxito ou insucesso dos programas (OLIVEIRA, 2004).

Neste sentido, sabendo que as consequências das reformas no trabalho docente afetam a questão da construção da autonomia, pode-se elencar alguns elementos de discussão, como: Frente a essa realidade complexa e de profundas transformações sobre o Trabalho docente, quais são os limites e as possiblidades de autonomia no exercício da docência? Contudo, antes faz-se necessário refletir sobre: O que é autonomia? Seria apenas a capacidade de autogoverno, de independência, de autossuficiência? Na próxima seção discute-se o conceito de autonomia dentro de uma perspectiva que a compreende inserida numa visão política e de integração social.

\section{AUTONOMIA PROFISSIONAL DOCENTE: ESTUDANDO O CONCEITO EM CONTRERAS}

A compreensão do termo autonomia pode adquirir diferentes sentidos, a depender do contexto em que se dá. Além disso, o autor Contreras (2012), ressalta o fato de que, na maioria das vezes, a difusão desse conceito tem se dado de maneira superficial, sob a forma de slogans. Ele ainda nos adverte que sob a forma de slogans, o real significado do termo não é esclarecido e dessa 
forma considera-se importante compreender a partir de quem discute a temática a expressão em sua significância mais complexa.

Em se tratando de uma discussão acerca da autonomia, como salienta Selma Garrido Pimenta, no prefácio à edição brasileira da obra A autonomia de Professores de José Contreras, o autor é um expoente na discussão do conceito que ao "desnudá-lo" nos auxilia na compreensão do papel fundamental do professor para a construção de um processo de democratização escolar e social. Desta forma, a discussão teórica ora apresentada, tem como base a obra supracitada, o que não significa que não haja outros autores que deem conta dessa discussão, mas que para o propósito estabelecido, a obra em questão apresenta os elementos necessários para uma compreensão mais ampla do conceito.

Para Contreras (2012), é necessário romper com “essa espécie de sortilégio" que se construiu em torno do conceito de autonomia e buscar compreender os diferentes significados que "se escondem" por trás de um discurso falacioso e que não expressa na sua totalidade suas implicações políticas educativas e na prática profissional. Nesse sentido, é mais que importante, é urgente resgatar e reconstruir o valioso significado do tema da autonomia do professor.

Na obra supracitada de Contreras (2012), o autor discute o tema da autonomia em três partes. Na primeira, discute-se o conceito atrelado a um outro igualmente importante quando se trata do trabalho docente, qual seja o da profissionalidade. Nesse sentido, a discussão é perpassada por questões como a proletarização e precarização do trabalho do professor, o significado do "ser profissional" e as dicotomias e ambiguidades que a busca pela profissionalidade oculta.

$\mathrm{Na}$ segunda parte, o autor aborda o conceito de autonomia dentro de três tradições de formação de professores: a da racionalidade técnica, a que defende o profissional reflexivo e a que apresenta o professor como intelectual crítico.

Na terceira parte da obra, procura-se estabelecer uma visão mais ampla do entendimento do conceito de autonomia, considerando as condições pessoais, institucionais e sociopolíticas que "uma autonomia profissional deveria ter, que não signifique nem individualismo, nem corporativismo, tampouco submissão burocrática ou intelectual” (CONTRERAS, 2012, p. 30). E, por fim, aborda-se a ideia de autonomia dentro do contexto das reformas recentes.

Não é o objetivo deste trabalho apresentar uma síntese desta obra de Contreras (2012), logo, a parte na qual se debruçará com maior ênfase a fim de retirar ideias fundamentais para nossa discussão está contida na terceira e na última parte, no entanto, faz-se necessário salientar que as 
demais partes são tão fundamentais quanto e que por vezes, serão exploradas, mesmo não sendo o foco.

Ao longo da obra Contreras (2012), aponta algo que considera fundamental para a compreensão da autonomia, qual seja a ideia de que autonomia não pode ser construída de forma isolada, sem intercâmbio, sem apoio, sem relação com os pares. Para tanto, é necessário superar uma visão meramente técnica do trabalho do professor, mas de igual modo a de uma reflexão que não analise as condições estruturais do contexto social, político, cultural e econômico e como essas condições afetam a prática.

Para um plano dessa natureza é preciso que os professores "intelectualizem" seu trabalho (SMYTH, 1987c), isto é, questionem criticamente sua concepção da sociedade, da escola, do ensino, o que significa não só assumirem a responsabilidade pela construção e utilização do conhecimento teórico, mas também terem o compromisso de transformação do pensamento e da prática dominante (p. 173).

Dito isto, pode-se compreender que a autonomia do professor passa pela apreensão do conhecimento teórico, o que implica qualidade na formação (inicial e contínua), e compromisso ético com a transformação social. A redução da atividade docente a uma atividade de mera reprodução de prescrições externas indica a perda de significado, de sentido, de autonomia. E a perda de autonomia, nesse sentido, indica um processo de desumanização do trabalho. Desta forma, como salienta Contreras "a reinvindicação da autonomia não é apenas uma exigência trabalhista pelo bem dos funcionários. O é também pelo bem da educação” (2012, p. 212).

Outra questão apontada por Contreras (2012), diz respeito ao reducionismo da autonomia às decisões estritamente relacionadas aos aspectos mais imediatos da atuação do professor, ou seja, em que as perspectivas de análise estão relacionadas aos problemas internos da sala de aula. Autonomia não é sobre decidir qual a tarefa aplicar, qual a sequência dessas atividades, quais espaços serão utilizados, etc. Ainda que estes aspectos também revelem expressões da autonomia profissional, ela não pode estar reduzida a essa compreensão.

Para Contreras (2012), a autonomia tem uma perspectiva coletiva, dialógica, intercambial. Ou seja, ela está para além da sala de aula pois se "constrói na dialética entre convicções pedagógicas e as possibilidades de realiza-las" e também na "conexão com as pessoas com as quais se trabalha". Desse modo, a autonomia profisssional não possui um padrão fixo de atuação e não se constitui numa construção solitária.

A autonomia profissional não significa, dessa perspectiva, o isolamento do restante dos colegas, nem tampouco oposição a intervenção social na educação ou o princípio 
de responsabilidade pública. Pelo contrário, a ideia de autonomia, entendida como exercício, como construção, deve se desenvolver em relação ao encargo prático de uma tarefa moral, da qual se é publicamente responsável, e que deve ser socialmente participada (p. 219).

De acordo com Contreras, é importante considerar que a construção de uma autonomia profissional real requer um distanciamento crítico. Para o autor

A responsabilidade profissional dos professores é estarem suficientemente conectados com suas comunidades para entender suas demandas e compreender os interesses de seus alunos, mas distantes o suficiente para poderem cultivar nos seus alunos o distanciamento crítico que lhes permita reconsiderar estes interesses e demandas frente a outros com os quais entra em conflito (CONTRERAS, 2012, p. 222)

Ou seja, a autonomia não se define apenas pela mediação dos interesses da comunidade, pois deste modo ela estaria limitada pela experiência presente e não daria conta de estabelecer uma crítica à essas demandas. A autonomia profissional, nessa perspectiva representa a defesa de "um programa político para a sociedade e um compromisso social com a profissão" (CONTRERAS, 2012, p. 224) o que implica compreender o ensino num contexto de tensões em relação ao seu sentido e às funções que possa cumprir.

É importante compreender que a autonomia adquire o sentido de emancipação quando permite pensar e questionar as próprias concepções de ensino e de sociedade, no entanto, isso envolve compreender também que as respostas obtidas a partir desses questionamentos são sempre parciais e incompletas, daí a importância de compreender nossa insuficiência, do autoconhecimento, da necessidade de olhar não apenas para nós, para nosso interior, mas para os outros e de buscar na relação com os outros "outras posições e outras parcialidades" (CONTRERAS, 2012, p. 226).

A dimensão afetiva e emocional também é apresentada como base para o desenvolvimento de uma autonomia profissional. Para Contreras (2012) é necessário prestar atenção aos nossos sentimentos. A autonomia não se reduz a um elemento puramente racional, mas como afirma o autor "o desenvolvimento emocional é indubitavelmente importante para uma autonomia profissional madura" (p. 229), o que não significa emocionalismo ou irracionalismo, mas a compreensão da dimensão humana do trabalho docente.

Tão importante quanto às questões anteriormente ressaltadas, Contreras (2012) salienta que a construção de uma autonomia profissional se realiza mediante a participação nos debates, nos espaços de discussão, bem como no compartilhamento do conhecimento e das práticas, 
desenvolvendo espaços de discussão. Para o autor "a autonomia dos professores só pode ser defendida apoiando a necessidade do debate educacional com e entre aqueles que assumem o protagonismo e a responsabilidade da prática” (p. 245).

A partir das discussões ora apresentadas, pode-se considerar que algumas dimensões são fundamentais na construção da autonomia docente, dentre elas o compromisso com a transformação social. Pensar autonomia, requer ter consciência do papel político e social que a escola desempenha. Requer empenho em construir uma rede com os pares para estabelecer espaços de reflexão e de debate, a competitividade entre os profissionais promovida pelas reformas que se pautam em uma lógica capitalista de mercado só tende a agravar os problemas educacionais, é necessário buscar o diálogo e a parceria. Requer comprometimento ético com a formação integral, garantida a todos os cidadãos brasileiros, e nesse sentido perceber como a educação é afetada pelas contradições sociais e se posicionar diante dessas contradições.

\section{A AUTONOMIA NO CONTEXTO DAS REFORMAS EDUCACIONAIS}

Como já visto anteriormente as reformas desencadeadas a partir dos anos 1990 no Brasil impactaram (e impactam) o trabalho docente. São diversas e, por vezes nefastas as consequências dessas políticas, pautadas na lógica de mercado, sobre a atividade do professor. Num contexto como esse, por vezes é difícil encontrar espaços para a construção de uma autonomia plena.

Vimos que para Contreras (2012), por exemplo, a autonomia é construída no diálogo com o outro, num processo de intercâmbio dialógico. Contudo, Freitas, ao discutir as reformas de caráter neoliberal que se desencadearam no Brasil, a partir dos anos 1990, adverte que num contexto de avaliação externa a "colocação dos profissionais de educação em processos de competição entre si e entre escolas levará a diminuição da possibilidade de colaboração entre estes” (2012, p. 390), indicando um limite para a construção da autonomia profissional. Desse modo, pode-se perceber que, no contexto brasileiro, as avaliações em larga escala restringem a construção da autonomia no sentido apontado por Contreras, qual seja, a da autonomia como uma construção coletiva.

Além disso, com relação às políticas de avaliação externa, outro elemento que pode se configurar como entrave para um exercício autônomo do professor são "as políticas de responsabilização (que) pressionam os professores a obter desempenho sempre crescente de seus alunos" (FREITAS, 2012, p. 391) e isso, muitas vezes leva a uma prática mecânica, desprovida de sentido, de reflexão, cuja única intenção passa a ser alcançar bons resultados. 
Nesse caso, de acordo com Contreras (2012), “dissolvem a possibilidade de criação e sustentação coletiva dos próprios vínculos sociais, para transformar a todos em dependentes de normas externas” (p. 241), impossibilitando uma concepção fluida de autonomia, que se sustente no desejo de entendimento mútuo, confiança e deliberação social.

E ainda, pode-se dizer que esse controle e regulação por meio de avaliações externas, "produzem um sentimento de impotência, associada a necessidade de sobreviver, que tem levado a fraude" (CONTRERAS, 2012, p. 392), prática que é contrária a uma postura integra, necessária para a autonomia, que de acordo com Contreras (2012), exige comprometimento ético.

Gatti (2004), tendo como base a realidade educacional brasileira de formação docente, ao discorrer acerca de elementos que compõem práticas educativas significativas elenca a emergência “atitudes éticas" entre os interlocutores como um dos elementos imprescindíveis para uma prática exitosa.

Outro elemento que pode ser compreendido como um limite à construção da autonomia diz respeito a ambiguidade na compreensão do termo. Como discutido por Oliveira (2004) ao tempo que se apresenta como possibilidade de liberdade de ação, o discurso político em torno do tema está impregnado de "culpabilização", de fazer com que os professores se sintam diretamente responsáveis pelos resultados indesejados, ignorando as condições externas a atuação em sala de aula.

Há ainda outros aspectos dessas reformas que impactam, direta ou indiretamente, o trabalho do professor e, por consequência o desenvolvimento de sua autonomia. No entanto, não se pretende apresentar uma crítica exaustiva, de modo que pareça impossível nesse contexto desenvolver uma prática autônoma. É possível que em algum momento o professor, na construção de sua autonomia tenha como entrave um desses ou outros elementos, sequer mencionados. É certo que é necessário que haja espaço, afinal, como constituir autonomia sem espaço para isso? Nesse sentido, é necessário encontrar possibilidades de construir espaço para o exercício da autonomia mesmo num contexto em que ela é "sufocada" por reformas neoliberais, afinal, como afirma Contreras (2012), a autonomia não é sobre a ausência de incertezas ou inseguranças, mas a capacidade de reconhecêlas, problematiza-las e enfrenta-las.

Ludke e Boing (2004) sinalizam que uma dessas possibilidades se dá por meio da pesquisa e da parceria. Para eles, por meio dessas alternativas, aos professores "abre-se uma perspectiva capaz de lhes permitir, com mais autonomia, lidar com as transformações cada vez mais aceleradas, no mundo da educação" (p. 1177). 
Contreras (2012) corrobora com a importância das parcerias, e, para além disso destaca outra questão essencial, que diz respeito ao papel da sociedade na construção da autonomia como um processo dinâmico e recíproco.

Assim como a autonomia dos professores deve basear-se nas vinculações com a sociedade e no reconhecimento dos direitos desta, buscando o diálogo, da mesma forma, a comunidade social deve basear sua ação no reconhecimento dos professores e da pretensão de diálogo. Não só os professores devem construir sua identidade e sua prática de um modo dinâmico e fluido, senão que também a comunidade social deve fazer o mesmo, reconhecendo assim a necessidade e o direito de que os professores constituam seu trabalho de forma autônoma (p. 136)

Para além do que já foi dito (e certamente ainda há muito a se dizer) é necessário enxergar nas crises possibilidades de mudança. A história da escola, bem como do trabalho docente se apresenta como o resultado das lutas e conflitos, em que se constrói e se reconstrói.

O diálogo, a parceria, a reflexão, o conhecimento, a resistência, o compromisso social com a educação como um processo democrático são, certamente, elementos imprescindíveis na luta por uma sociedade mais justa, mais igualitária e para formar sujeitos mais críticos e autônomos, bem como para construir a própria autonomia.

\section{CONCLUSÃO}

Como já explicitado anteriormente, não há neste trabalho a pretensão de esgotar essa discussão, sobretudo por se tratar de um tema essencial para o desenvolvimento de uma prática transformadora, mas de caráter muito complexo.

Pode-se ver que as reformas que se desencadearam afetaram de diversas formas o trabalho docente e, por consequência na autonomia do professor distorcendo seu significado, reduzindo-a a um slogan, compreendendo-o como a possibilidade de decidir acerca das questões internas a sala de aula, ou mesmo considerando que é uma forma dos docentes não prestarem contas sobre o que fazem, e além disso limitaram o espaço para o exercício de uma prática autônoma.

Contudo, faz-se necessário compreender a autonomia de forma ampliada, considerando que ela exige um compromisso real do professor com um ideal democrático de educação. Sobretudo, num cenário de constantes ataques a educação, ao professor e a escola e de violação de direitos fundamentais, a autonomia não é apenas importante, mas urgente para que se possa resistir frente a esses ataques. A ampliação desse horizonte deve ter como base, nas palavras de Contreras (2012), 
“o que (a autonomia) deveria ser e ainda não é” e isso exige a problematização e a consciência dos propósitos e das finalidades da escola, bem como do papel que ela desempenha nos âmbitos social, político e cultural.

Conclui-se que de fato as reformas que vem sendo implantadas desde meados dos anos de 1990 afetam o trabalho docente e, por consequência, muitas vezes dificultam a construção da autonomia. No entanto, não se pode perder de vista a finalidade da prática educativa, qual seja a de assegurar o pleno desenvolvimento dos sujeitos e sua inserção ativa e crítica na sociedade, desse modo, para além das dificuldades o olhar do professor deve estar posto numa perspectiva de autonomia profissional que caminhe consonância com um projeto democrático de educação que promova a autonomia social.

\section{REFERÊNCIAS}

CATANI, Denice B. et al. Docência, Memória e gênero. Campinas, SP: Papirus, 1997.

BALL, Stephen J. Reformar escolas/Reformar professores e os terrores da performatividade. Revista Portuguesa de Educação, Braga, Portugal, v. 15, n. 002. p. 3-23, 2002.

CONTRERAS, José. Autonomia de professores. Trad. Sandra Trabucco Valenzuela. 2. ed. São Paulo: Cortez, 2012.

CORTELlA, Mario Sergio. A escola e o conhecimento. 13. ed. São Paulo: Cortez, 2009.

CUNHA, Maria Isabel. O tema da Formação de Professores: Trajetórias e tendências do campo na pesquisa e na ação. Educação e Pesquisa, São Paulo, n. 3. p. 609-625, jul./set. 2013.

FREITAS, Luiz Carlos. Os reformadores empresariais da educação: da desmoralização do magistério a destruição do sistema público de educação. Educ. Soc., Campinas, v. 33, n. 119, p. 379-404, abr.-jun. 2012

GATTI, Bernardete A. Educação, escola e formação de professores: políticas e impasses. Educar em Revista, Curitiba, n. 50, p. 51-67, out./dez. 2013.

HYPOLITO, Alvaro M.; VIEIRA, Jarbas S.; PIZZI, Laura C. V. Reestruturação curricular e auto-intensificação do trabalho docente. Currículo sem Fronteira, v.9, n. 2, p. 100-112, jul./dez. 2009.

LUDKE, Menga; BOING, Luiz A. Caminhos da Profissão e da Profissionalidade docentes. Educação e Sociedade, Campinas, vol. 25, n. 89, p. 1159-1180, set./dez. 2004.

OLIVEIRA, Dalila Andrade. A reestruturação do trabalho Docente: Precarização e Flexibilização. Educação e Sociedade, Campinas, vol.25, n. 89, p. 1127-1144, set./dez. 2004.

PACHECO, José. Escola da Ponte: formação e transformação da educação. Petrópolis, RJ: Vozes, 2010. 


\section{RESUMO}

Nesse trabalho apresenta-se uma discussão acerca das reformas que ocorreram a partir dos anos 90 , do século $\mathrm{XX}$, considerando-se um contexto neoliberal, e como elas impactaram o trabalho docente e, na autonomia profissional do professor. Trata-se de um trabalho de natureza bibliográfica, cujas fontes de pesquisa foram livros e artigos que tratam o tema sob uma perspectiva crítica. Tem-se como referenciais teóricos, Contreras (2012); Gatti (2013) Oliveira (2004); Freitas (2012), entre outros. A partir das leituras pode-se depreender que as reformas educacionais na década de 1990 impactaram de forma direta a autonomia docente com novas formas de regulação do trabalho. Conclui-se que, apesar dessa constatação, ainda é necessário buscar possibilidades de resistência.

Palavras-chave: Reformas Educacionais. Trabalho Docente. Autonomia profissional docente.

\section{THE TEACHER PROFESSIONAL AUTONOMY AND THE EDUCATIONAL REFORMS FROM THE 1990 YEARS: LIMITS AND POSSIBILITIES}

\section{ABSTRACT}

This work introduces a discussion about the reforms that occurred from the 90s, in the XX century, considering a neoliberal context, and how did they impact the teaching work and, in the teacher professional autonomy. It is a work of a bibliographic nature, whose sources of the searches were books and articles that treats the theme under a critical perspective. It has as theoretical references, Contreras (2012); Gatti (2013), Oliveira (2004); Freitas (2012), among others. From the readings it can understand that the educational reforms in 1990 decade directly impacted in the autonomy of the teacher with new ways of regulation about the work. Concludes that, even though this confirmation, it is still necessary look for possibilities of resistance.

Keywords: The teacher professional autonomy. Educational Reforms. Teacher work.

\section{LA AUTONOMÍA PROFESIONAL Y LAS REFORMAS EDUCACIONALES DE LOS AÑOS 1990: LÍMITES Y POSIBILIDADES}

\section{RESUMEN}

En este trabajo se presenta una discusión acerca de las reformas que ocurrieron a partir de los años 90 , del siglo XX, considerándose un contexto neoliberal, y como ellas impactaron el trabajo docente y, en la autonomía profesional del profesor. Se trata de un trabajo de naturaleza bibliográfica, cuyas fuentes de investigación fueron libros y artículos que tratan el tema sobre una perspectiva crítica. Se tiene como referenciales teóricos, Contreras (2012); Gatti (2013) Oliveira (2004); Freitas (2012), entre otros. A partir de las lecturas se puede desprender que las reformas educacionales en la década de 1990 impactaron de forma directa la autonomía docente con nuevas formas de regulación del trabajo. Se concluye que, a pesar de esa constatación, aun es necesario buscar posibilidades de resistencia.

Palabras clave: Autonomía Profesional Docente. Reformas Educacionales, Trabajo Docente.

Submetido em 30 de julho de 2019

Aprovado em 01 de setembro de 2019 